OLIVEIRA, Rafael Niebuhr Maia de; SILVA, Everaldo da. Intervenção estatal nas taxas de juros remuneratórios aplicadas pelas instituições financeiras aos consumidores no Brasil. Revista Eletrônica Direito e Política, Programa de Pós-Graduação Stricto Sensu em Ciência Jurídica da UNIVALI, Itajaí, v.12, n.3, 30 quadrimestre de 2017. Disponível em: www.univali.br/direitoepolitica - ISSN 19807791

\title{
INTERVENÇÃO ESTATAL NAS TAXAS DE JUROS REMUNERATÓRIOS APLICADAS PELAS INSTITUIÇÕES FINANCEIRAS AOS CONSUMIDORES NO BRASIL
}

\author{
STATE INTERVENTION IN REMUNERATION INTEREST RATES APPLIED BY \\ FINANCIAL INSTITUTIONS TO CONSUMERS IN BRAZIL
}

\section{Rafael Niebuhr Maia de Oliveira ${ }^{1}$ \\ Everaldo da Silva²}

SUMÁRIO: Introdução; 1 Sistema Financeiro Nacional em fase de Reestruturação Capitalista; 2 Limitação de Juros Bancários no Brasil; 3 Formas de controle de juros como forma de obter a Sustentabilidade Econômica no país; Considerações finais; Referências das fontes citadas

\section{RESUMO}

Este trabalho visa abordar a sustentabilidade econômica, através do estudo da intervenção estatal na economia, especialmente no que tange à limitação das taxas de juros remuneratórios aplicados pelas instituições financeiras no país. 0 trabalho visa, em síntese, mostrar através da pesquisa doutrinária, operacionalizadas pelo método indutivo, que embora a análise histórico-sociológica indique os danos à sustentabilidade financeira provocados por uma política de juros bancários completamente desregulada e sem qualquer intervenção do Estado, a prática jurídica, especialmente após a Emenda Constitucional n. 40 não admite a intervenção na taxa de juros praticadas pelas Instituições Financeiras. Outrossim, salvo quando elas extrapolam a taxa média de mercado, a qual é apenas calculada e divulgada pelo Banco Central, sem qualquer intervenção deste nem de qualquer outro órgão estatal

PALAVRAS-CHAVE: Intervenção do Estado; Juros remuneratórios; Sustentabilidade econômica

\footnotetext{
${ }^{1}$ Bacharel em Direito pela Unifebe - Brusque/SC; Especialista pela Uniderp; Advogado inscrito nos quadros da OSB/SC sob o n. 25.993. Professor de Direito das Obrigações, Responsabilidade Civil, Propriedade Intelectual e Criminologia do IBES/Sociesc - Blumenau - SC; Professor das Disciplinas de Direito Processual Civil V da Unifebe - Brusque/SC. Professor de Pós-Graduação (MBA) junto ao Instituto Valor Humano/Univali das Disciplinas de Contratos Imobiliários e Contratos Agrários. Professor de Pós-Graduação (MBA) junto a Unifebe da disciplina de Procedimento Especiais (Processo Civil). Professor de Pós-Graduação (MBA) junto ao INPG da Disciplina de Direito Empresarial. E-mail: rafaelmaiaadv@gmail.com. Currículo Lattes: http://lattes.cnpq.br/9285964965375059.

2 Sociólogo. Bacharel e Licenciado em Ciências Sociais (FURB). Mestre em Desenvolvimneto Regional (FURB). Doutor em Sociologia Política (UFSC). Professor e Pesquisador no Centro Universitário de Brusque e na Faculdade Metropolitana de Blumenau. E-mail: prof.evesilva@gmail.com. Currículo Lattes: http://lattes.cnpq.br/0029501595403337
} 
OLIVEIRA, Rafael Niebuhr Maia de; SILVA, Everaldo da. Intervenção estatal nas taxas de juros remuneratórios aplicadas pelas instituições financeiras aos consumidores no Brasil. Revista Eletrônica Direito e Política, Programa de Pós-Graduação Stricto Sensu em Ciência Jurídica da UNIVALI, Itajaí, v.12, n.3, 30 quadrimestre de 2017. Disponível em: www.univali.br/direitoepolitica - ISSN 19807791

\section{ABSTRACT}

This study aims at approaching economic sustainability, through the study of State intervention in the economy, mainly regarding the limitation of remuneration interest rates applied by financial institutions in the country. The paper seeks to show, through doctrine research applying the inductive method, that although the sociological-historical analysis indicates damage to the financial sustainability provoked by a totally deregulated bank interest policy and without any State intervention, the legal practice, mainly after the Constitutional Amendment no 40 which does not admit intervention in the interest rates used by the institutions, except for when the market average rate is extrapolated, which is only calculated and disclosed by the Central Bank, without any intervention of this bank or any other State agency.

KEY-WORDS: State intervention. Compensation interest. Economic sustainability.

\section{INTRODUÇÃO}

Constitui-se como objeto deste artigo científico a pesquisa no campo da sociologia e do direito brasileiro acerca da importância ou não da intervenção do estatal na economia com vistas a alcançar a sustentabilidade econômica, especialmente no que tange à limitação das taxas de juros aplicadas pelas Instituições Financeiras no Brasil.

O progressivo aumento das taxas de juros bancários, muito superiores aos aplicados em outros países pelo mundo, vem fazendo com que estas alcancem cifras muito expressivas, superando em alguns produtos - como no caso do cartão de crédito - o patamar de quatrocentos por cento ao ano. Taxas desta ordem podem comprometer a sustentabilidade econômica, causando concentração de riqueza no mercado financeiro, em detrimento do poder de compra da população e da pujança econômica dos setores produtivos, motivos estes que justificam a presente pesquisa.

A pesquisa se origina de dois problemas, quais sejam: a) É possível alcançar a sustentabilidade econômica sem a participação do Estado como regulador e limitador de direitos? b) A limitação dos juros remuneratórios pode ser implementada no país e, sem que se afronte o texto constitucional?

Diante dos problemas acima, propuseram-se, respectivamente, as seguintes 
OLIVEIRA, Rafael Niebuhr Maia de; SILVA, Everaldo da. Intervenção estatal nas taxas de juros remuneratórios aplicadas pelas instituições financeiras aos consumidores no Brasil. Revista Eletrônica Direito e Política, Programa de Pós-Graduação Stricto Sensu em Ciência Jurídica da UNIVALI, Itajaí, v.12, n.3, 30 quadrimestre de 2017. Disponível em: www.univali.br/direitoepolitica - ISSN 19807791

hipóteses: a) a própria natureza das corporações parece indicar a impossibilidade de se obter sustentabilidade sem o controle e regulamentação do Estado. Isso porque, conforme Bakan ${ }^{3}$, as corporações se tratam de entidades desprovidas de personificação, cujo objetivo principal é o de gerar lucros, o que geralmente é feito sem que os efeitos sociais colaterais sejam considerados empecilhos.

Nesse sentido, a participação do Estado nesse processo, não necessariamente como detentor dos meios de produção, mas como regulador da economia, se mostra necessária para que outros objetivos sociais, que não só os lucros, sejam observados e postos em local de destaque; b) após a Emenda Constitucional n. 40, a limitação de juros aplicados pelas Instituições Financeiras foi extirpada do ordenamento jurídico, de forma que atualmente a questão se encontra a mercê das regras de mercado. Todavia, a mudança no texto constitucional não inviabiliza que novas iniciativas legislativas surjam com este escopo, nem tampouco, impede que juízes se apoiando em princípios gerais do direito e nas regras estabelecidas no Código de Defesa do Consumidor, limitem os juros em casos em que estes sejam cobrados em patamar aviltante.

Para se atingir os objetivos perseguidos, inicialmente, foi discutido sobre o sistema financeiro nacional em fase de Reestruturação Capitalista, para na sequência se examinar as vantagens e desvantagens financeiras e sociais da intervenção do Estado na economia. Na sequência, abordar-se-á à questão dos juros limitação de juros bancários no Brasil, examinando suas regras legais, bem como as suas hipóteses de limitação, para por fim, examinar-se com base na doutrina e em esporádicas passagens pelas legislações, se a limitação da taxa de juros remuneratórios praticadas por Instituições Financeiras no Brasil, podem conduzir a sustentabilidade econômica de maneira benéfica.

\footnotetext{
${ }^{3}$ BAKAN, Joel. A corporação, a busca patológica por lucro e poder.
} 
OLIVEIRA, Rafael Niebuhr Maia de; SILVA, Everaldo da. Intervenção estatal nas taxas de juros remuneratórios aplicadas pelas instituições financeiras aos consumidores no Brasil. Revista Eletrônica Direito e Política, Programa de Pós-Graduação Stricto Sensu em Ciência Jurídica da UNIVALI, Itajaí, v.12, n.3, $3^{\circ}$ quadrimestre de 2017. Disponível em: www.univali.br/direitoepolitica - ISSN 19807791

No desenvolvimento desta pesquisa será utilizado o método indutivo, ou seja, pesquisar e identificar as partes de um fenômeno e colecioná-las de modo a ter uma percepção ou conclusão geral.

$\mathrm{Na}$ investigação, fez-se p uso da técnica do referente, das categorias e do conceito operacional, através de pesquisa doutrinária, cujas referências das obras citadas serão colacionadas ao final. Por opção metodológica, tratar-se-á primordialmente dos aspectos destacados da doutrina nacional relacionada ao tema abordado, com breves e esporádicas análises legais sobre o tema, além de alguns destaques acerca da legislação de outros países quanto ao tema. Os pressupostos conceituais serão trazidos ao decorrer do desenvolvimento da pesquisa, através de notas de rodapé, assim como as referências ao longo do texto.

\section{SISTEMA FINANCEIRO NACIONAL EM FASE DE REESTRUTURAÇÃO CAPITALISTA}

A crise que surgiu no país no limiar da década de 60 e desembocaria no golpe militar de 1964, tinha sua matriz no modelo econômico que havia sido instaurado, muito concentrador de renda e produtor de desigualdades sociais, o qual reproduzia a articulação de setores da burguesia nacional com o capital internacional. Desde a reforma bancária de 1964, o setor bancário cresceu a partir do surgimento de grandes conglomerados e de extensas redes de agências espalhadas por todo o país.

O movimento de expansão e reorganização do sistema financeiro favoreceria o grande capital financeiro privado internacional e nacional, contemplando os requisitos da acumulação monopolista. Além disso, os governos militares fizeram crescer uma política específica, incentivando a "concentração e a centralização bancárias".

Dentre as várias medidas estatais que aceleraram a concentração da riqueza no setor privado, Ary Minella (1988) destaca: criação de estímulos fiscais para fusões e incorporações; política de corte à abertura de novas agências bancárias privadas, a participação econômica direta e as coações do Banco Central favoráveis aos 
OLIVEIRA, Rafael Niebuhr Maia de; SILVA, Everaldo da. Intervenção estatal nas taxas de juros remuneratórios aplicadas pelas instituições financeiras aos consumidores no Brasil. Revista Eletrônica Direito e Política, Programa de Pós-Graduação Stricto Sensu em Ciência Jurídica da UNIVALI, Itajaí, v.12, n.3, 30 quadrimestre de 2017. Disponível em: www.univali.br/direitoepolitica - ISSN 19807791

bancos de maior porte, nos processos de fusões e incorporações ${ }^{4}$.

Conforme menciona Karl Marx (1989) ${ }^{5}$, esse processo de acumulação da riqueza revela-se na concentração crescente dos meios de produção sob o domínio de capitalistas individuais, de um lado; e, de outro, na disputa entre os capitais individuais que concorrem entre si mesmos. A partir disso, o autor diferencia conceitualmente concentração de centralização:

Essa dispersão do capital social em muitos capitais individuais ou a repulsão entre seus fragmentos é contrariada pela força de atração existente entre eles. Não se trata mais da concentração simples dos meios de produção e de comando sobre o trabalho, a qual significa acumulação. O que temos agora é a concentração dos capitais já formados, a supressão de sua autonomia individual a expropriação do capitalista pelo capitalista, a transformação de muitos capitais pequenos em poucos capitais grandes. Este processo se distingue do anterior porque pressupõe apenas alteração na repartição dos capitais que já existem e estão funcionando [...] O capital se acumula aqui nas mãos de um só, porque escapou das mãos de muitos noutra parte. Esta é a centralização propriamente dita, que não se confunde com a acumulação e a concentração ${ }^{6}$

A organização institucional do sistema financeiro nacional incluiu grande número de empresas financeiras especializadas em diferente formas de captação de recursos financeiros, entre elas, bancos de investimento, companhias de seguro, sociedades de crédito imobiliário e cadernetas de poupança, instituições com vínculos à operação da Bolsa de Valores etc. Neste sentido, as empresas de grande porte aumentaram sua atuação no mercado, mantendo o controle de um grande contingente de empresas não bancárias.

4 MINELlA, Ary. Banqueiros, Organização e Poder no Brasil. Rio de Janeiro: Espaço e Tempo/ANPOCS, 1988, p. 171.

5 MARX, Karl. O Capital, Crítica da Economia Política. Livro I, vol.2, 12a edição, Rio de Janeiro: Bertrand Brasil, 1989a.

${ }^{6}$ MARX, K. O Capital - Crítica da Economia Política. Livro I, vol. 1, 13a. Edição. Rio de Janeiro: Bertrand Brasil, 1989b, p. 7. 
OLIVEIRA, Rafael Niebuhr Maia de; SILVA, Everaldo da. Intervenção estatal nas taxas de juros remuneratórios aplicadas pelas instituições financeiras aos consumidores no Brasil. Revista Eletrônica Direito e Política, Programa de Pós-Graduação Stricto Sensu em Ciência Jurídica da UNIVALI, Itajaí, v.12, n.3, 30 quadrimestre de 2017. Disponível em: www.univali.br/direitoepolitica - ISSN 19807791

A partir de 1980, o mercado brasileiro passou a sofrer modificações mais estruturais, tendo continuidade logo após as diversas políticas de ajuste econômico desde 1990 com a adoção do receituário liberal, elevando sensivelmente os índices de desemprego no país.

É mister afirmarmos que além das pressões financeiras convencionais, agora temos como exigência a intervenção dos países desenvolvidos no que tange a governança estatal, ou seja, os governos são obrigados a agir conforme orientações feitas por instituições como FMI (Fundo Monetário Internacional) e Banco Mundial.

O assim chamado "neoliberalismo" dos anos 90 foi um período de concentração de riqueza, que se deu por meio da segregação dos mercados de créditos. Procedeuse à abertura financeira indiscriminada, à apreciação do câmbio, à elevação substancial dos juros internos. Houve uma quebra de pequenas e médias empresas, um empobrecimento da classe média, abrindo espaço para a oligopolização da economia. Tivemos o aumento dos grandes grupos, modernizados e competitivos; também a combinação de alta tributação e juros elevados, praticamente estagnando os investimentos públicos, o poder aquisitivo e o mercado interno.

O que podemos afirmar, é que a política recomendada pelos países desenvolvidos é deveras conveniente para eles, porque retornando um pouco no tempo veremos que as recomendações de hoje para os países em desenvolvimento são políticas que eles mesmos não adotariam, ou seja, como bem afirma o economista alemão do século XIX, Friedrich List (apud CHANG, 2004) ao estudar a história da indústria nascente inglesa:

[...] a recém-criada indústria nacional não teria chance de sucesso em livre concorrência com as estrangeiras, estabelecidas havia muito mais tempo (as italianas, as hanseáticas, as belgas e as holandesas) .... Portanto, mediante um sistema de restrições, privilégios e incentivos, 
OLIVEIRA, Rafael Niebuhr Maia de; SILVA, Everaldo da. Intervenção estatal nas taxas de juros remuneratórios aplicadas pelas instituições financeiras aos consumidores no Brasil. Revista Eletrônica Direito e Política, Programa de Pós-Graduação Stricto Sensu em Ciência Jurídica da UNIVALI, Itajaí, v.12, n.3, 30 quadrimestre de 2017. Disponível em: www.univali.br/direitoepolitica - ISSN 19807791

trataram de transplantar para o solo nacional a riqueza, o talento e o espírito empreendedor dos estrangeiros. ${ }^{7}$

List (1885) afirma ainda que o livre-comércio somente traz benefícios para países que têm o mesmo nível de desenvolvimento industrial, mas não para os países que estão em processo de desenvolvimento, como é o caso do Brasil ${ }^{8}$

Minella (1988) $)^{9}$ afirma que, em 1980, 10 entre os 15 maiores bancos de investimento estavam associados ao capital internacional, tendo na mesma época um predomínio de empresas dominadas pelo capital estrangeiro, entre elas estão as instituições de arrendamento mercantil (leasing). O capital externo tinha maior presença em instituições do sistema não monetário, devido a uma política restritiva do governo quanto à participação de bancos estrangeiros no sistema de bancos comerciais. As relações do sistema financeiro interno com o capital internacional apoiavam-se no conceito de reciprocidade, ou seja, se aplicaria ao capital estrangeiro a ser investido no país o mesmo "tratamento jurídico concedido ao capital nacional em igualdade de condições". ${ }^{10}$

Verifica-se no Brasil um movimento de endividamento externo em pleno período chamado de "milagre", entre 1968 e 1973, quando ao mesmo tempo as altas taxas de crescimento econômico no país ocorrem com a estabilização dos índices inflacionários em torno de $20 \%$ a $25 \%$ ao ano. A esse ciclo de crescimento econômico Paul Singer (1976) atribui os seguintes motivos:

Se havia algum milagre num período relativamente prolongado de crescimento com pouca inflação, este se explicava fundamentalmente: (a) pela maneira como a repartição da renda foi disciplinada mediante a substituição

\footnotetext{
7 CHANG, Ha-Joon. Chutando a escada - a estratégia do desenvolvimento em perspectiva histórica. São Paulo: Editora UNESP, 2004, p. 15.

8 CHANG, Ha-Joon. Chutando a escada - a estratégia do desenvolvimento em perspectiva histórica. São Paulo: Editora UNESP, 2004.

9 MINELlA, Ary. Banqueiros, Organização e Poder no Brasil. Rio de Janeiro: Espaço e Tempo/ANPOCS, 1988.

10 Lei 4.131, de 03.09.1962
} 
OLIVEIRA, Rafael Niebuhr Maia de; SILVA, Everaldo da. Intervenção estatal nas taxas de juros remuneratórios aplicadas pelas instituições financeiras aos consumidores no Brasil. Revista Eletrônica Direito e Política, Programa de Pós-Graduação Stricto Sensu em Ciência Jurídica da UNIVALI, Itajaí, v.12, n.3, 30 quadrimestre de 2017. Disponível em: www.univali.br/direitoepolitica - ISSN 19807791

da barganha coletiva no mercado de trabalho por uma política salarial rígida, centralizada e - do ponto de vista da acumulação de capital - perfeitamente eficaz; e (b) pela crescente integração internacional das economias capitalistas, acarretando alterações na divisão mundial do trabalho, que acabaram proporcionando amplo influxo de capital estrangeiro no Brasil. ${ }^{11}$

Após o golpe militar de 1964 no Brasil não apenas se manteve como se aprofundou as relações de dependência e de subdesenvolvimento, característica das economias de países vizinhos. Florestan Fernandes (1981) analisa a invasão súbita e impetuosa do capitalismo monopolista no Brasil, evidenciando seu caráter de desenvolvimento dependente do dinamismo das economias hegemônicas e do mercado capitalista mundial:

Desde que esta (dominação externa) se mantenha, o que tem
lugar é um desenvolvimento capitalista dependente e,
qualquer que seja o padrão para o qual ele tenda, incapaz de
saturar todas as funções econômicas, socioculturais e políticas
que ele deveria preencher no estágio correspondente do
capitalismo. É claro que o crescimento capitalista se dá,
acelerando a acumulação de capital ou a modernização
institucional, mas mantendo, sempre, a expropriação
capitalista externa e o subdesenvolvimento relativo, como
condições e feitos inelutáveis. ${ }^{12}$

Os bancos privados nacionais e estrangeiros sediados no Brasil tiveram grande influência no endividamento externo. Os bancos comerciais e de investimento contrataram empréstimos diretamente no exterior, para serem transferidos às empresas nacionais. Simultaneamente, isso implicou em altos índices de lucratividade do setor bancário privado e intensificou o endividamento externo do país.

Minella (1988) ${ }^{13}$ observa, o apoio de determinada parte da burguesia bancária

11 SINGER, Paul. A crise do "Milagre": Interpretação Crítica da Economia Brasileira. Rio de Janeiro: Paz e Terra, 1976, p. 87.

12 FERNANDES, Florestan. A Revolução Burguesa no Brasil - Ensaio de Interpretação Sociológica. $3^{a}$ edição, Rio de Janeiro: Zahar Editores, 1981, p. 87.

13 MINELLA, Ary. Banqueiros, Organização e Poder no Brasil. Rio de Janeiro: Espaço e 
OLIVEIRA, Rafael Niebuhr Maia de; SILVA, Everaldo da. Intervenção estatal nas taxas de juros remuneratórios aplicadas pelas instituições financeiras aos consumidores no Brasil. Revista Eletrônica Direito e Política, Programa de Pós-Graduação Stricto Sensu em Ciência Jurídica da UNIVALI, Itajaí, v.12, n.3, 30 quadrimestre de 2017. Disponível em: www.univali.br/direitoepolitica - ISSN 19807791

nacional às pressões praticadas pelo grande capital transnacional para que aumentasse a abertura do mercado financeiro do país. Isto também ocorria através de simultâneos investimentos em empresas de setores diversos da economia. Conforme dados do autor, no início dos anos 80, oito dos maiores bancos nacionais privados tinham associações com o capital estrangeiro em 46 empresas no mínimo. ${ }^{14}$

O sistema financeiro nacional obtinha rentabilidade líquida muito mais elevada que a de empresas vinculadas a outros setores econômicos. Segundo Cerqueira \& Amorim (1997) ${ }^{15}$, os bancos apoiados nos ganhos de floating oferecidos pelas altas taxas de inflação nas décadas de 70 e 80 e no financiamento da dívida pública, caracterizaram alta lucratividade comparando-se a outros setores. De fato, ocorre uma relação de causalidade que se estabeleceu entre a rentabilidade bancária e o processo inflacionário, no decorrer dos anos 80 , no qual a economia teve uma taxa média anual inflacionaria sempre superior a $200 \%$.

No ano de 1986, os bancos passaram por um novo contexto. Com o congelamento de preços causado pelo Plano Cruzado, a fonte de lucros que ocorreria através do processo inflacionário esgotou, ainda que momentaneamente. Para Cerqueira \& Amorim (1997), com a queda de rentabilidade, o setor percebeu o "inchaço de sua máquina administrativa e o gigantismo de sua rede de atendimento, adequadas a um regime inflacionário crônico, mas completamente disfuncionais em um contexto de estabilidade econômica". ${ }^{16}$

Tempo/ANPOCS, 1988.

14 MINELLA, Ary. Banqueiros, Organização e Poder no Brasil. Rio de Janeiro: Espaço e Tempo/ANPOCS, 1988, p. 213.

15 CERQUEIRA, H. e AMORIM, W. Evolução e característica do emprego no Setor Bancário. In: CARLEIAL, L. e VALLE, R. Reestruturação produtiva e mercado de trabalho no Brasil, São Paulo: Hucitec/ABET, 1997.

${ }^{16}$ CERQUEIRA, H. e AMORIM, W. Evolução e característica do emprego no Setor Bancário. In: CARLEIAL, L. e VALLE, R. Reestruturação produtiva e mercado de trabalho no Brasil, São Paulo: Hucitec/ABET, 1997, p. 399. 
OLIVEIRA, Rafael Niebuhr Maia de; SILVA, Everaldo da. Intervenção estatal nas taxas de juros remuneratórios aplicadas pelas instituições financeiras aos consumidores no Brasil. Revista Eletrônica Direito e Política, Programa de Pós-Graduação Stricto Sensu em Ciência Jurídica da UNIVALI, Itajaí, v.12, n.3, $3^{\circ}$ quadrimestre de 2017. Disponível em: www.univali.br/direitoepolitica - ISSN 19807791

A essa comprovação segue-se um "ligeiro ajuste administrativo", que se baseou essencialmente na demissão de bancários. Neste mesmo ano, 109.000 postos de trabalho foram eliminados no setor. Em contrapartida, a economia no geral criou mais de um milhão de novos empregos, amenizando de certa forma o impacto ocorrido.

No decorrer do mesmo período a inflação retornou a patamares elevados, mas os bancos continuaram atentos aos riscos da queda dos lucros, quando fosse atingida a estabilização econômica.

De fato, continuaram os ajustes em suas estruturas, passando do ponto de vista institucional por um processo de desregulamentação, que teve início em 1988, no limiar da promulgação da nova Constituição. No entanto, às mudanças vieram acompanhadas do aumento dos investimentos em automação. Os bancos ficaram entre as primeiras empresas no país a destinar o uso do computador, colocando como prioridade sua disputa no mercado pela busca de maior agilidade nas informações. A partir de 1986, o processo de automação foi destinado a uma maior sintonia entre os bancos e seus clientes, isto acompanhando os consideráveis investimentos em telecomunicações, difundindo-se o uso de redes locais e sistemas on line, e serviços de autoatendimento, home banking e "agências virtuais".

Ao mesmo tempo, novas estratégias de mercado foram definidas, principalmente com a criação de novos produtos e serviços, havendo uma retomada na captação de recursos no exterior, desenvolvendo uma vasta variedade de fundos de aplicação, tais como, renda fixa, commodities, ações entre outros.

Já, desde o governo Fernando Collor (1990-1992), o movimento de abertura comercial e financeira subordinava cada vez mais a política econômica e monetária brasileira aos interesses do grande capital transnacional, tendo como seus legítimos representantes os organismos financeiros internacionais como o FMI (Fundo Monetário Internacional), o Banco Mundial e o BID (Banco Interamericano de Desenvolvimento). 
OLIVEIRA, Rafael Niebuhr Maia de; SILVA, Everaldo da. Intervenção estatal nas taxas de juros remuneratórios aplicadas pelas instituições financeiras aos consumidores no Brasil. Revista Eletrônica Direito e Política, Programa de Pós-Graduação Stricto Sensu em Ciência Jurídica da UNIVALI, Itajaí, v.12, n.3, 30 quadrimestre de 2017. Disponível em: www.univali.br/direitoepolitica - ISSN 19807791

Verificou-se, no entanto, que, essa expansão das operações financeiras mundiais não se estendeu de modo universal. Chesnais (1996) identifica o caráter excludente destes movimentos, quando esclarece o significado do termo "mundialização do capital":

[...] Ligar o termo "mundialização" ao conceito de capital significa dar-se conta de que, graças ao seu fortalecimento e às políticas de liberalização que ganhou de presente em 197981 e cuja imposição foi depois continuamente ampliada, o capital recuperou a possibilidade de volta a escolher, em total liberdade, quais os países e camadas sociais que têm interesse para ele. ${ }^{17}$

A internacionalização financeira no Brasil, vinculou-se à dinâmica produtiva e prosperou mediante o endividamento externo das empresas. Nos anos 90, a nova inserção internacional do país ocorreu através de um conjunto de fatores externos e internos, atrelados a dois movimentos, de um lado, aos movimentos atuais do mercado financeiro internacional; e, de outro, às novas implementações e reformas neoliberais ocorridas no Brasil.

A partir das eleições presidenciais de 1989, ocorreu um consenso à adoção das políticas de estabilização e reformas estruturais neoliberais, propostas pelo Consenso de Washington. Segundo Fiori (1993), esse consenso desenvolvia-se em torno do reconhecimento da natureza estrutural da crise econômica e política que abalava a sociedade brasileira da segunda metade dos anos 80 . Sinalizava o esgotamento do modelo de desenvolvimento adotado no país desde a década de 50, apontando para a necessidade urgente de um programa de ajuste macroeconômico e de reestruturação produtiva. ${ }^{18}$

O governo Collor adotou e concretizou um amplo programa de "estabilização" e de reformas institucionais de cunho liberalizante, cujos os mesmos seriam adotados

\footnotetext{
17 CHESNAIS, François. A Mundialização do Capital. São Paulo: Xamã, 1996, p. 18.

18 FIORI, J.L. "Ajuste, Transição e Governabilidade: o Enigma Brasileiro". In: TAVARES, M.C. e FIORI, J.L. Desajuste Global e Modernização Conservadora. Rio de Janeiro: Paz e Terra, 1993, p. 3.
} 
OLIVEIRA, Rafael Niebuhr Maia de; SILVA, Everaldo da. Intervenção estatal nas taxas de juros remuneratórios aplicadas pelas instituições financeiras aos consumidores no Brasil. Revista Eletrônica Direito e Política, Programa de Pós-Graduação Stricto Sensu em Ciência Jurídica da UNIVALI, Itajaí, v.12, n.3, 30 quadrimestre de 2017. Disponível em: www.univali.br/direitoepolitica - ISSN 19807791

posteriormente por novos governos. Fiori (1993) menciona as seguintes medidas, compostas no programa econômico do governo de Fernando Collor: reforma administrativa, patrimonial e fiscal do Estado; renegociação da dívida externa; abertura comercial; liberação dos preços; desregulamentação salarial; e, sobretudo, prioridade absoluta para o mercado como orientação e caminho para uma nova integração econômica internacional e modernidade institucional. ${ }^{19}$

Para Daniela Prates, os processos de abertura financeira de uma economia desenvolvem-se em três níveis, dos quais o Brasil se encontra no primeiro:

No primeiro nível, são permitidos tanto o endividamento de residentes no mercado internacional de capitais quanto 0 investimento de não-residentes no mercado financeiro doméstico - essas transações são denominadas inward transations. O segundo nível de abertura envolve a posse de ativos externos e a transferência de capital por parte de residentes, e o endividamento de não-residentes no mercado interno - transações denominadas outward transations. Nesse nível de abertura, existe total conversibilidade da conta de capital. O terceiro nível de abertura refere-se à conversibilidade interna da moeda, ou seja, à liberdade de posse e de relações de débito e crédito entre residentes em (ou denominados em) moeda estrangeira. ${ }^{20}$

Paralelamente, cresceram os investimentos diretos estrangeiros no sistema financeiro nacional, principalmente na participação acionária em instituições financeiras locais e a instalação de subsidiárias e de filiais no nosso mercado. Afirma-se que, essa expansão foi viabilizada pelas políticas nacionais favoráveis ao capital estrangeiro nos anos 90 , as quais aboliram ou diminuíram as restrições à participação externa nos sistemas financeiros locais.

A abertura do sistema financeiro ao capital estrangeiro teve maior crescimento ao

\footnotetext{
19 FIORI, J.L. "Ajuste, Transição e Governabilidade: o Enigma Brasileiro". In: TAVARES, M.C. e FIORI, J.L. Desajuste Global e Modernização Conservadora. Rio de Janeiro: Paz e Terra, 1993, p. 153.

20 PRATES, D. Abertura Financeira e Vulnerabilidade Externa: A Economia Brasileira Na Década de 90. Dissertação de Mestrado, Instituto de Economia da Unicamp. Campinas, 1997, p. 7.
} 
OLIVEIRA, Rafael Niebuhr Maia de; SILVA, Everaldo da. Intervenção estatal nas taxas de juros remuneratórios aplicadas pelas instituições financeiras aos consumidores no Brasil. Revista Eletrônica Direito e Política, Programa de Pós-Graduação Stricto Sensu em Ciência Jurídica da UNIVALI, Itajaí, v.12, n.3, 30 quadrimestre de 2017. Disponível em: www.univali.br/direitoepolitica - ISSN 19807791

longo do governo do presidente Fernando Henrique Cardoso, que reforçou a implementação de programas neoliberais no Brasil. Como prioridade na sua política econômica, o programa de estabilização monetária foi assegurado pelo crescente investimento de capitais externos e pela sobrevalorização cambial. O chamado "Plano Real", implantado aos poucos desde 199321, intensificou as medidas de ajuste fiscal, liberalização financeira, privatização e abertura comercial.

As instituições financeiras externas com ampla liberdade de acesso no país escolheram entre a participação no capital social de bancos privados nacionais, a aquisição do controle acionário de instituições através dos processos de privatização/liquidação, bem como, a instalação/expansão de sucursais e subsidiárias no mercado brasileiro. Na década de 90, especialmente nos últimos anos, a participação estrangeira nos ativos totais dos bancos brasileiros aumentou de $11 \%$ em dezembro de 1994 para 24,8\% em junho de $1998^{22}$. Quase duplicou o número de bancos controlados pelo capital externo no país.

A reestruturação do sistema financeiro, também decorreu dos programas de privatização de bancos estatais. O governo brasileiro praticou na segunda metade da década passada, uma perceptível redução da presença do Estado no sistema.

Simultaneamente, abrindo o mercado nacional ao capital externo, estimulando os processos de fusões e incorporações, privatizando instituições estatais, o governo brasileiro continua a seguir a cartilha neoliberal para o crescente desenvolvimento capitalista, tornando o sistema financeiro nacional cada vez mais sob influência de instituições financeiras internacionais e pelos especuladores do capital privado.

\footnotetext{
21 A implantação do Plano Real teve origem no (PAI) Programa de Ação Imediata, adotado em junho de 1993, tentando-se obter equilíbrio nas contas públicas. Ocorre a introdução da URV (Unidade Real de Valor) como referência de um padrão estável de valor em fevereiro de 1994 e a criação da nova unidade do sistema monetário nacional: o real, a partir de junho de 1994.

22 FREITAS, M.C. e PRATES, D. "Abertura Financeira na América Latina: as experiências da Argentina, Brasil e México. In: Revista Economia e Sociedade. Campinas, 1998.
} 
OLIVEIRA, Rafael Niebuhr Maia de; SILVA, Everaldo da. Intervenção estatal nas taxas de juros remuneratórios aplicadas pelas instituições financeiras aos consumidores no Brasil. Revista Eletrônica Direito e Política, Programa de Pós-Graduação Stricto Sensu em Ciência Jurídica da UNIVALI, Itajaí, v.12, n.3, 30 quadrimestre de 2017. Disponível em: www.univali.br/direitoepolitica - ISSN 19807791

\section{LIMITAÇÃO DE JUROS BANCÁRIOS NO BRASIL}

Diante da abordagem histórica acima tratada, pode-se verificar a instalação de políticas neoliberais na economia nacional, especialmente no que tange à parcela reservada ao mercado financeiro, que obtém seu faturamento a partir das taxas de juros, instituto este no qual se debruçará neste momento da pesquisa.

Neste contexto, é importante destacar que a palavra "juro" tem origem etimológica do latim jure, de jus, júris, denota da língua portuguesa a singularidade de designar os interesses do dinheiro, com a expressão "juro". Já no plural, o termo "juros" indica interesse, ganhos, lucros, vantagens que o detentor do capital recebe de alguém que não possui capital, mas necessariamente precisa usufruir, também pode ser definido como os frutos civis oriundos de um capital que foi emprestado a outrem. Portanto, juros representam o ganho do capital que está sendo usufruindo por um terceiro, e não o seu próprio titular. Insta constar, que os juros se diferem da correção monetária, pois não indicam ganhos, lucros ou rendimentos, mas simplesmente a manutenção da moeda, pela perda do seu poder de compra ${ }^{23}$.

Portanto, correspondem os juros aos rendimentos ou frutos do capital emprestado, em suma, empresta-se uma importância a terceiro, e pelo fato de permanecer a coisa ou os bens em poder do contratante, cobra-se uma espécie de remuneração pela fruição do capital, chamada de juros, os quais, portanto, encontram sua natureza e justificativa na remuneração pelo uso ou permanência da coisa própria com outra pessoa, mediante contrato prévio ${ }^{24}$.

Os juros convencionais compensatórios são aqueles pagos pelo uso consentido do capital, decorrente de negócio jurídico entre as partes. Esse negócio jurídico surge

\footnotetext{
23 SCAVONE JUNIOR, Luiz Antonio. Direito Imobiliário: Teoria e Prática. 7. ed. Rio de Janeiro: Forense, 2014. p. 491-492.

${ }^{24}$ RIZZARDO, Arnaldo. Juros no código civil de 2002. Revista de Direito Bancário, do Mercado de capitais e da Arbitragem. São Paulo: Editora Revista dos Tribunais. Ano 6, n. 22, outubrodezembro de 2003. p. 53-77.
} 
OLIVEIRA, Rafael Niebuhr Maia de; SILVA, Everaldo da. Intervenção estatal nas taxas de juros remuneratórios aplicadas pelas instituições financeiras aos consumidores no Brasil. Revista Eletrônica Direito e Política, Programa de Pós-Graduação Stricto Sensu em Ciência Jurídica da UNIVALI, Itajaí, v.12, n.3, 30 quadrimestre de 2017. Disponível em: www.univali.br/direitoepolitica - ISSN 19807791

de um contrato mútuo (tipicamente mútuo feneratício), ou concessão de crédito através de um financiamento concedido para aquisição de produtos ou prestação de serviços ${ }^{25}$.

Já em 1933, o legislador nacional previu a limitação de juros, identificando neste um perigoso artifício de concentração de capital desprovido de produção, prática que chamava de "usura", que inclusive emprestou nome ao decreto lei 22.626/33 - ainda em vigor - que define no art. $1^{\circ}$ a expressa vedação a qualquer cobrança em contrato de juros superiores ao dobro da taxa legal.

Por ser uma lei aberta, eis que para sua aplicação necessita se complementar o conceito de "taxa legal", esta mudou sua aplicabilidade prática ao longo dos anos, na medida em que as taxas legais de juros eram estipuladas e alteradas. No âmbito civil, por exemplo, o antigo código que vigiu até janeiro de 2003, estipulava a taxa de $0,5 \%$ ao mês como limite de juros moratório, aumentado a partir atual Código Civil, para um por cento ao mês.

Antes disto, em 1988 com a promulgação da Constituição Federal - não a toa chamada por muitos de a Constituição Cidadã - o legislador constituinte manifesta sua preocupação com a regulamentação do mercado financeiro, dedicando uma seção específica para a matéria junto ao art. 192.

Mais especificamente, quanto aos juros praticados pelas Instituições Bancárias sujeitas ao Sistema Financeiro Nacional, estipulou no parágrafo $3^{\circ}$ do art. 192, o seguinte:

As taxas de juros reais, nelas incluídas comissões e quaisquer outras remunerações direta ou indiretamente referidas à concessão de crédito, não poderão ser superiores a doze por cento ao ano; a cobrança acima deste limite será conceituada como crime de usura, punido, em todas as suas modalidades, nos termos que a lei determinar. ${ }^{26}$

\footnotetext{
25 SCAVONE JUNIOR, Luiz Antonio. Direito Imobiliário: Teoria e Prática. 7. ed. Rio de Janeiro: Forense, 2014. p. 506.

26 BRASIL, Constituição da república federativa do Brasil. Brasília, DF: Senado, 1988. art.
} 
OLIVEIRA, Rafael Niebuhr Maia de; SILVA, Everaldo da. Intervenção estatal nas taxas de juros remuneratórios aplicadas pelas instituições financeiras aos consumidores no Brasil. Revista Eletrônica Direito e Política, Programa de Pós-Graduação Stricto Sensu em Ciência Jurídica da UNIVALI, Itajaí, v.12, n.3, 30 quadrimestre de 2017. Disponível em: www.univali.br/direitoepolitica - ISSN 19807791

Assim, estabeleceu-se no Brasil a proibição de cobrança de juros superiores a $12 \%$ ao ano, sem que na época se gerasse alvoroço ou brados contra a intervenção do Estado e a favor do liberalismo e da dita "mão invisível" de Adam Smith. Todavia, as Instituições não se adequaram a norma constitucional, continuando a cobrar taxas superiores ao limite estabelecido, o que levou muitos consumidores a buscar o Poder Judiciário, onde obtiveram vitórias judiciais - em que pese a existência de uma tese, a época, de que tal norma não possuiria aplicabilidade imediata, firmada posteriormente pela Súmula Vinculante n. $7^{27}$-, conforme se exemplifica com um julgado do ano de 2001, cuja ementa abaixo segue.

As taxas de juros reais, nelas incluídas comissões e quaisquer outras remunerações direta ou indiretamente referidas à concessão de crédito, não poderão ser superiores a doze por cento ao ano; a cobrança acima deste limite será conceituada como crime de usura, punido, em todas as suas modalidades, nos termos que a lei determinar. (Ap. Cív. n. 97.003790-2, de Criciúma, Rel. Des. Pedro Manoel Abreu, DJ de 11.6.01)

Eis que neste cenário de insegurança jurídica resultante das diversas interpretações aplicadas por diversos Tribunais pelo país, surge a Emenda Constitucional n. 40, que exclui do texto constitucionais os parágrafos do art. 192, extinguindo assim por completo a limitação constitucional de juros do sistema financeiro nacional.

Na prática o que se fez com a emenda constitucional n. 40 foi retirar do texto constitucional, importante dispositivo de interesse nacional que possibilitava ao Estado controlar a taxa de juros compensatórios, impossibilitando ganhos exacerbados dos bancos e agentes financeiros às custas de toda a cadeia produtiva nacional. Assim, a única forma que o Estado brasileiro tem de influenciar na política de juros praticada pelas Instituições Financeiras é se utilizando de seus dois

192.

${ }^{27}$ A norma do $\S 3^{\circ}$ do art. 192 da Constituição, revogada pela EC 40/2003, que limitava a taxa de juros reais a $12 \%$ ao ano, tinha sua aplicação condicionada à edição de lei complementar 
OLIVEIRA, Rafael Niebuhr Maia de; SILVA, Everaldo da. Intervenção estatal nas taxas de juros remuneratórios aplicadas pelas instituições financeiras aos consumidores no Brasil. Revista Eletrônica Direito e Política, Programa de Pós-Graduação Stricto Sensu em Ciência Jurídica da UNIVALI, Itajaí, v.12, n.3, 30 quadrimestre de 2017. Disponível em: www.univali.br/direitoepolitica - ISSN 19807791

"players" no mercado, a Caixa Econômica Federal - empresa pública federal - e o Banco do Brasil - sociedade de economia mista com controle acionário do Governo Federal, para que reduzam suas taxas para influenciar, através da competitividade de mercado, que as demais instituições sejam obrigadas a seguir por um mesmo caminho.

Contudo, em que pese a citada emenda constitucional retirar do Estado o poder de controlar os juros no país, entregando-o à mão invisível do mercado, eis que é este quem determina qual será a taxa média de mercado, os juros quando fixados acima deste limite imposto pelo próprio mercado poderão ser limitadas. O Superior Tribunal de Justiça 28 , já se manifestou no sentido de combater os juros exacerbados cobrados pelas Instituições Financeiras, estipulando como taxa média de mercado os índices extraídos do Banco Central do Brasil, o que foi confirmado pela edição da súmula $296^{29}$ do mesmo tribunal.

E ainda, cabe destacar o posicionamento do Supremo Tribunal Federal ${ }^{30}$ no mesmo contexto:

RECURSO EXTRAORDINÁRIO - MATÉRIA LEGAL E AUSÊNCIA DE PREQUESTIONAMENTO.1. Na interposição deste agravo foram observados os pressupostos de recorribilidade. A agravante providenciou o traslado das peças obrigatórias e respeitou o prazo de dez dias. Registro estar a peça subscrita por profissional da advocacia regularmente credenciado. A Turma Recursal acolheu pedido formulado em recurso, ante os seguintes fundamentos (folhas 289 e 291): RECURSO CÍVEL. AÇÃO REVISIONAL. CARTÃO DE CRÉDITO. LIMITAÇÃO

28 BRASIL, Superior Tribunal de Justiça (STJ). REsp: 1112879 PR. Relator: Ministra Nancy Andrighi. Data de Julgamento: 12/05/2010. Segunda Seção. Data de Publicação: 19/05/2010. Disponível em: <https://stj.jusbrasil.com.br/jurisprudencia/9271881/recurso-especial-resp1112879-pr-2009-0015831-8/inteiro-teor-14302984>. Acesso 16. nov. 2014. Grifei.

29 Súmula 296 - Os juros remuneratórios, não cumuláveis com a comissão de permanência, são devidos no período de inadimplência, à taxa media de mercado estipulada pelo Banco Central do Brasil, limitada ao percentual contratado.

\footnotetext{
30 BRASIL, Supremo Tribunal Federal (STF). AI: 759682 Go. Relator: Min. Marco Aurélio. Data de Julgamento 06/08/2009. Data de Publicação: 03/09/2009 Disponível em: <https://stf.jusbrasil.com.br/jurisprudencia/14760907/agravo-de-instrumento-ai-759682-go-stf>. Acesso 16. nov. 2014. Grifei.
} 
OLIVEIRA, Rafael Niebuhr Maia de; SILVA, Everaldo da. Intervenção estatal nas taxas de juros remuneratórios aplicadas pelas instituições financeiras aos consumidores no Brasil. Revista Eletrônica Direito e Política, Programa de Pós-Graduação Stricto Sensu em Ciência Jurídica da UNIVALI, Itajaí, v.12, n.3, 30 quadrimestre de 2017. Disponível em: www.univali.br/direitoepolitica - ISSN 19807791

DE JUROS. INADMISSIBILIDADE. COMPETÊNCIA DE FIXAÇÃO PELO COPOM - COMITÊ DE POLÍTICA MONETÁRIA. PREVALÊNCIA DA LIVRE PACTUAÇÃO. INAPLICABILIDADE DA LEI DE USURA, DECRETO No 22.626/33. X - In casu, é de se reconhecer que o usuário do cartão de crédito não é um desavisado das taxas de juros aplicadas, nesta modalidade creditícia, tanto que estão ao seu alcance, nos próprios extratos bancários, sendo, pois, ciente do seu custo, mas, por outro lado, considerando sua onerosidade, já que são taxas bastante díspares das demais operações financeiras do mercado, deve, então, os juros remuneratórios, no contrato em questão, serem reduzidos à taxa média do Banco Central do Brasil, reajustando-se o débito pelo índice mais benigno, juros de mora de $1 \%$ ao mês e multa de $2 \%$, expurgando-se a comissão de permanência, conquanto não pode ser cumulada com outros encargos.[...] A decisão recorrida está calcada em interpretação conferida ao Código de Defesa do Consumidor. A taxa de juros objeto do contrato foi afastada ante constatação de abusividade da cláusula. Em momento algum, a Corte de origem adotou entendimento contrário ao teor do inciso II do artigo $5^{\circ}$ da Constituição Federal. O que se percebe é que a articulação em torno das garantias constitucionais parte da interpretação conferida à normas estritamente legais. Consoante dispõe a alínea "a" do inciso III do artigo 102 da Carta da Republica, o cabimento do extraordinário pressupõe conclusão conflitante com a lei básica, o que não ocorreu no caso destes autos. 2. Conheço deste agravo e o desprovejo.3. Publiquem. Brasília, 6 de agosto de 2009. Ministro MARÇO AURÉLIO Relator.

Conforme interpretação acima, tendo em vista a jurisprudência dos Tribunais Superiores, que atuando supletivamente ante a completa ausência de limitação legal de juros das instituições financeiras no país, tem-se que a única limitação expressa às taxas de juros praticadas por instituições desta natureza se encontram na exacerbação da média das taxas aplicadas pelo próprio mercado, a qual não encontra qualquer regulação pelo Banco Central, a quem cabe somente realizar e divulgar a média aritmética das taxas praticas pelo mercado, que é a quem, em análise final, cabe a regulação da matéria, pós Emenda Constitucional n. 40. 
OLIVEIRA, Rafael Niebuhr Maia de; SILVA, Everaldo da. Intervenção estatal nas taxas de juros remuneratórios aplicadas pelas instituições financeiras aos consumidores no Brasil. Revista Eletrônica Direito e Política, Programa de Pós-Graduação Stricto Sensu em Ciência Jurídica da UNIVALI, Itajaí, v.12, n.3, 30 quadrimestre de 2017. Disponível em: www.univali.br/direitoepolitica - ISSN 19807791

\section{FORMAS DE CONTROLE DE JUROS COMO FORMA DE OBTER A SUSTENTABILIDADE ECONÔMICA NO PAÍS}

Conforme abordado, foi extirpado do sistema jurídico brasileiro a previsão expressa de limitação da taxa de juros praticados por instituições bancária, porém o que se analisa a partir deste ponto, é a possibilidade desta relação contratual eivado pelos princípios consumeristas, tornar-se um limitador das taxas de juros praticadas por estas instituições financeiras.

Quanto à aplicabilidade das normas do Código de Defesa do Consumidor às relações bancárias, esta já superou as discussões judiciais, tendo sido pacificada pelo STJ na súmula $297^{31}$. Afinal, os bancos existem para realizar intermediações financeiras, sendo que excluí-los da aplicabilidade e proteção da legislação consumerista, é retirar a abrangência de todo o Código de Defesa do Consumidor, bem como os artigos 50, XXXII, e 170, V da Constituição Federal ${ }^{32}$.

Cumpre, ainda, salientar que na Constituição Federal, lançou-se como objetivo fundamental da República o de 'construir uma sociedade livre, justa e solidária', 'ex vi' do art. 30, I da CF. Reza, ainda, a Constituição quando cita os princípios gerais da atividade econômica (art. 170, caput) que está "(...) tem por fim assegurar a todos a existência digna, conforme os ditames da justiça social."

Daí surge o questionamento se o Código de Defesa do Consumidor, no que tange à matéria referente aos juros aplicados pelas Instituições Financeiras não encontraria óbice no texto constitucional, de forma que nesta seara não poderiam ser aplicadas normas do direito do consumidor, sob pena de se ferir as normas constitucionais referentes a matéria.

\footnotetext{
31 O Código de Defesa do Consumidor é aplicável às instituições financeiras

32 OLIVEIRA. Eduardo Ribeiro de. A fixação da taxa de juros e o Código de Defesa do Consumidor. Revista Jus Navigandi. Teresina, ano. 14. no 2323. 10. Nov. 2009. Disponível em <http://jus.com.br/artigos/13829. Acesso em: 14 jun. 2015.
} 
OLIVEIRA, Rafael Niebuhr Maia de; SILVA, Everaldo da. Intervenção estatal nas taxas de juros remuneratórios aplicadas pelas instituições financeiras aos consumidores no Brasil. Revista Eletrônica Direito e Política, Programa de Pós-Graduação Stricto Sensu em Ciência Jurídica da UNIVALI, Itajaí, v.12, n.3, 30 quadrimestre de 2017. Disponível em: www.univali.br/direitoepolitica - ISSN 19807791

Em síntese, tem-se que a Lei 8.078/1990 não materializa a defesa do consumidor (art. 50. XXXII; e 170, V), e também não confronta o princípio da adequada condução do SFN (art. 192), haja vista que o Código de Defesa do Consumidor, cuja natureza é ordinária, não menciona estipulação as operações submetidas à Lei 4.595/1964, das quais se determina fixação da taxa de juros, cuja competência é do Conselho Monetário Nacional ${ }^{33}$. Tanto é assim, que o Supremo Tribunal Federal julgou pela total improcedência da ação direta de inconstitucionalidade, não se aplicando a técnica de interpretação suscitada pela requerente, neste caso, Confederação Nacional de Sistema Financeiro ${ }^{34}$.

Com efeito, entendo que os denominadores comuns a que chegou a orientação majoritária da Corte se reportam à existência de conflito apriorístico entre o Código do Consumidor e a Constituição Federal, porquanto a Lei 8.078/1990 não versa expressamente sobre estipulação de juros, e é possível conceber a existência de um âmbito próprio das relações de consumo aplicável às instituições financeiras e seus clientes. ${ }^{35}$ :

Por fim, nota-se que pela decisão do STF, a legislação consumerista não afronta o texto constitucional pelo argumento de que o Código de Defesa do Consumidor não contém disposição que disciplina a matéria cuja competência é da Lei 4.595/1964, que regulamenta o SFN, haja vista que foi recebida pela Carta Magna

33 OLIVEIRA. Eduardo Ribeiro de. A fixação da taxa de juros e o Código de Defesa do Consumidor. Revista Jus Navigandi. Teresina, ano. 14. no 2323. 10. Nov. 2009. Disponível em <http://jus.com.br/artigos/13829. Acesso em: 14 jun. 2015.

34 BRASIL, Supremo Tribunal Federal (STF). ADI-ED 2591DF. Relator: Min. Carlos Velloso. Data de Julgamento 07/06/2006. Tribunal do Pleno. Data de Publicação 29/09/2006 Disponível em: <https://stf.jusbrasil.com.br/jurisprudencia/760371/acao-direta-de-inconstitucionalidade-adi2591-df>. Acesso 16. nov. 2014. Grifei.

35 BRASIL, Supremo Tribunal Federal (STF). ADI-ED 2591DF. Relator: Min. Carlos Velloso. Data de Julgamento 07/06/2006. Tribunal do Pleno. Data de Publicação 29/09/2006 Disponível em: <https://stf.jusbrasil.com.br/jurisprudencia/760371/acao-direta-de-inconstitucionalidade-adi2591-df>. Acesso 16. nov. 2014. Grifei. 
OLIVEIRA, Rafael Niebuhr Maia de; SILVA, Everaldo da. Intervenção estatal nas taxas de juros remuneratórios aplicadas pelas instituições financeiras aos consumidores no Brasil. Revista Eletrônica Direito e Política, Programa de Pós-Graduação Stricto Sensu em Ciência Jurídica da UNIVALI, Itajaí, v.12, n.3, 30 quadrimestre de 2017. Disponível em: www.univali.br/direitoepolitica - ISSN 19807791

com status de lei complementar. Neste entendimento destaca-se o julgado do Egrégio Tribunal Federal da $5^{a}$ Região ${ }^{36}$ :

CIVIL. CONTRATO DE CARTÃO DE CRÉDITO. AÇÃO DE COBRANÇA. APLICAÇÃO DO CDC. LIMITAÇÃO DA TAXA DE JUROS A $12 \%$ AO ANO. CAPITALIZAÇÃO DOS JUROS. COMISSÃO DE PERMANÊNCIA. NÃ̃O CUMULAÇÃO. POSSIBILIDADE. I - Ação de cobrança proposta pela CEF contra Rômulo Carvalho correia Lima, pretendendo reaver crédito disponibilizado ao demandado por meio de contrato de abertura de crédito bancário, com cartão de crédito, e não pago. II- Apelação do particular alegando excesso na cobrança dos juros remuneratórios, capitalização dos juros e cumulação indevida dos encargos contratuais com a comissão de permanência. III - Aplica-se o CDC às operações efetuadas com instituições bancárias. Precedente. IV. No que diz respeito ao argumento referente à limitação dos juros remuneratórios ao patamar de $12 \%$ (doze por cento) ao, observa-se que a jurisprudência já assentou entendimento de que não existe tal limitação nos contratos bancários, firmados posteriormente à edição da Medida Provisória 1.963 - 17, como no caso em tela, esta Egrégia Corte já se orientou pela permissividade de tal prática. Precedentes. VI. Não há nenhum indício de que houve cumulação indevida de taxas com a comissão de permanência. A inadimplência do devedor ocasionou a incidência de juros de mora e multa, não havendo que se falar em cumulação abusiva. Precedentes. VII. Apelação improvida.

Destarte, salienta-se que as taxas de juros não podem ser reguladas pelo Código de Defesa do Consumidor, conforme já pacificado pela Jurisprudência, entretanto cabe ao Poder Judiciário quando constatado a cobrança de juros abusivos, regulálos de acordo com a média do mercado, neste sentido corrobora o entendimento do Tribunal de Justiça de Minas Gerais ${ }^{37}$ :

\footnotetext{
36 BRASIL, Tribunal Regional Federal da 5a Região. (TRF-5). AC: 75595020124058200. Relator: Desembargadora Federal Margarida Cantarelli. Data de Julgamento: 25/02/2014. Quarta Turma. Data de Publicação: 06/03/2014. Disponível em: <https://trf5.jusbrasil.com.br/jurisprudencia/25012448/ac-apelacao-civel-ac-75595020124058200-trf5>. Acesso 16. nov. 2014. Grifei.
}

37 MINAS GERAIS, Tribunal de Justiça. (TJ-MG). AC: $\mathbf{1 0 1 4 5 0 9 5 0 8 8 8 6 3 0 0 1}$ MG. Relator: José de Carvalho Barbosa. Data de Julgamento: 13/02/2014. Câmaras Cíveis. 13a Câmara Cível. Disponível em: <https://tj-mg.jusbrasil.com.br/jurisprudencia/119378837/apelacao-civel-ac- 
OLIVEIRA, Rafael Niebuhr Maia de; SILVA, Everaldo da. Intervenção estatal nas taxas de juros remuneratórios aplicadas pelas instituições financeiras aos consumidores no Brasil. Revista Eletrônica Direito e Política, Programa de Pós-Graduação Stricto Sensu em Ciência Jurídica da UNIVALI, Itajaí, v.12, n.3, 30 quadrimestre de 2017. Disponível em: www.univali.br/direitoepolitica - ISSN 19807791

\begin{abstract}
APELAÇÃO - REVISÃO CONTRATUAL - FINANCIAMENTO DE VEÍCULO - CDC - APLICABILIDADE - LIMITAÇÃO DA TAXA DE JUROS REMUNERATÓRIOS A $12 \%$ AO ANO INADMISSIBILIDADE - LIMITAÇÃO À TAXA MÉDIA DO MERCADO - POSSBILIDADE - CAPITALIZAÇÃO DOS JUROS PACTUAÇÃO EXPRESSA - LEGALIDADE. 1. Pacificado 0 entendimento no Colendo Superior Tribunal de Justiça de que as instituições financeiras não se sujeitam ao disposto na Lei de Usura, não indicando a fixação dos juros em patamar superior a $12 \%$ ao ano, por si só, abuso que autoriza a sua revisão pelo Poder Judiciário. A taxa de juros remuneratórios deve ser limitada à taxa média de mercado, caso tenha sido fixada em índice abusivo. É possível capitalização mensal de juros nos contratos firmados após a vigência da MP 1.963 $17 / 200$, reeditada sob o no $2.170 / 2001$, desde que tenha sido expressamente pactuado.
\end{abstract}

Ademais, destaca-se que o Superior Tribunal de Justiça, firmou tal posicionamento ao julgar a REsp 1.061.530/RS ${ }^{38}$, dos quais destacam-se as seguintes questões: a) que as instituições financeiras não se sujeitam à limitação da taxa de juros remuneratórios previstos na Lei de Usura - Súmula 596 do STF; b) A estipulação de juros remuneratórios superiores a $12 \%$ ao ano, por si só não indica abusividade; c) São inaplicáveis aos juros remuneratórios dos contratos de mútuo bancário as disposições do art. 591 c/c o art. 406 do CC/02; d) É admitida a revisão das taxas de juros remuneratórios em situações excepcionais, desde que caracterizada a relação de consumo e que a abusividade (capaz de colocar o consumidor em desvantagem exagerada art. 51, $\S 1^{0}$ do CDC) fique cabalmente demonstrada, antes às peculiaridades do julgamento em concreto

Ressalta-se que o Supremo Tribunal Federal adotou posicionamento semelhante ao julgar o Agravo de Instrumento no $759682 / \mathrm{GO}^{39}$, em sede de Recurso

10145095088863001-mg/inteiro-teor-119378880>. Acesso 16. nov. 2014. Grifei.

38 BRASIL, Superior Tribunal de Justiça (STJ). REsp 1.061.530 RS. Relator: Ministra Nancy Andrighi. Data de Julgamento: 22/10/2008. Segunda Seção. Disponível em: <https://stj.jusbrasil.com.br/jurisprudencia/2438811/recurso-especial-resp-1061530-rs-20080119992-4/inteiro-teor-1228758>. Acesso 16. nov. 2014. Grifei.

39 BRASIL, Supremo Tribunal Federal (STF). AI: 759682 GO. Relator: Min. Marco Aurélio. Data de Julgamento 06/08/2009. Data de Publicação: 03/09/2009 Disponível em: <https://stf.jusbrasil.com.br/jurisprudencia/14760907/agravo-de-instrumento-ai-759682-go-stf>. 
OLIVEIRA, Rafael Niebuhr Maia de; SILVA, Everaldo da. Intervenção estatal nas taxas de juros remuneratórios aplicadas pelas instituições financeiras aos consumidores no Brasil. Revista Eletrônica Direito e Política, Programa de Pós-Graduação Stricto Sensu em Ciência Jurídica da UNIVALI, Itajaí, v.12, n.3, 30 quadrimestre de 2017. Disponível em: www.univali.br/direitoepolitica - ISSN 19807791

Extraordinário, cujo relator Ministro Marco Aurélio, defendeu o posicionamento no sentido de que as taxas de juros praticadas pelas instituições financeiras, quando instituídas de forma abusiva, devem ser reguladas a taxa média de mercado.

Em síntese, observa-se que tanto os Tribunais, quanto o Superior Tribunal de Justiça, bem como o Supremo Tribunal Federal, reconhecem que o Código de Defesa do Consumidor não pode simplesmente limitar a taxa de juros praticada nas relações contratuais entre consumidor e instituições financeiras, contudo, destacam que os julgadores quando constatarem abusividade na taxa de juros cobradas pelas instituições financeiras, devem intervir de forma a regular a relação contratual, estipulando a taxa média de mercado dos juros, dada a interpretação do Código de Defesa do Consumidor.

Neste diapasão, extrai-se do voto do Eminente Ministro do STJ, Ruy Rosado de Aguiar, o seguinte:

As taxas de mercado podem ser aceitas para os negócios em geral quando houver efetiva concorrência, adequadamente fiscalizada pelo Estado, além da possibilidade real de escolha, o que de nenhum modo acontece. Quais as opções e o poder de negociar as cláusulas de contrato bancário que se permitem ao nosso pequeno agricultor, ou ao microempresário? Em recente relatório, divulgado pela Folha de São Paulo, afirmou o FMI que "os bancos no Brasil são pouco competitivos e funcionam como um oligopólio em que poucas instituições controlam o mercado. Se o Estado libera os juros e o Tribunal se recusa a afastar o abuso, algumas situações podem causar perplexidade. Junto aos autos, e invoco como razão de decidir, cópia do voto que proferi no REsp no 466979/RS, sobre o ponto. ${ }^{40}$

Em que pese a clarividente exposição do ministro, supra exposta, a prática jurídica no Brasil indica que após a Emenda Constitucional n. 40, foi excluído do ordenamento jurídico a possibilidade do Estado em limitar a taxa de juros

Acesso 16. nov. 2014. Grifei.

40 Min. Rel. Ruy Rosado de Aguiar - RESP 450844. 
OLIVEIRA, Rafael Niebuhr Maia de; SILVA, Everaldo da. Intervenção estatal nas taxas de juros remuneratórios aplicadas pelas instituições financeiras aos consumidores no Brasil. Revista Eletrônica Direito e Política, Programa de Pós-Graduação Stricto Sensu em Ciência Jurídica da UNIVALI, Itajaí, v.12, n.3, 30 quadrimestre de 2017. Disponível em: www.univali.br/direitoepolitica - ISSN 19807791

remuneratórios praticadas pelo mercado, exceção feita quando esta supera a média praticada pelas próprias Instituições Financeiras, deixando ao mercado, caminho aberto para através da formação de cartéis, explorarem a taxa de juros que melhor Ihes convier, independentemente do impacto que isto traga à sociedade brasileira.

\section{CONSIDERAÇÕES FINAIS}

Diante dos estudos apresentados acerca da Intervenção Estatal nas taxas de juros remuneratórios aplicadas pelas Instituições Financeiras aos consumidores no Brasil, pode-se confirmar a primeira hipótese de que a própria natureza das corporações parece indicar a impossibilidade de se obter sustentabilidade sem o controle e regulamentação do Estado.

Foi possível constatar o desenvolvimento e as transformações do capitalismo contemporâneo, como ele afeta a concorrência entre capitais, o seu impacto e consequências no Brasil, o qual passa nos últimos 4 (quatro) anos por uma série de alterações orientadas pelo cumprimento de uma agenda conservadora de ajustes econômicos e políticos. Esses ajustes, ao contrário, não contribuíram para minimizar o quadro já antigo de desigualdade social que caracteriza a sociedade brasileira, produzindo um agravamento da exclusão social. Não só o número de pessoas pobres cresceu, como também se tornou mais difícil de encontrar trabalho.

Buscando-se a resposta ao segundo problema desta pesquisa, buscou-se uma visão histórica-legislativa acerca da atuação regulatória do Estado sobre as taxas de juros praticadas pelo mercado financeiro, de onde observou-se que muito embora a Constituição da República, previsse a sua limitação à taxa de $12 \%$ ao ano, tal regulamentação cai por terra no ano de 2003 após o advento da Emenda Constitucional de n. 40, que simplesmente extingue esta previsão do texto constitucional.

Assim, diante da ausência legislativa acerca do tema, verificou-se que os Tribunais Superiores preenchem esta lacuna ao editarem a máxima de que "as taxas de 
OLIVEIRA, Rafael Niebuhr Maia de; SILVA, Everaldo da. Intervenção estatal nas taxas de juros remuneratórios aplicadas pelas instituições financeiras aos consumidores no Brasil. Revista Eletrônica Direito e Política, Programa de Pós-Graduação Stricto Sensu em Ciência Jurídica da UNIVALI, Itajaí, v.12, n.3, 30 quadrimestre de 2017. Disponível em: www.univali.br/direitoepolitica - ISSN 19807791

juros praticadas no mercado financeiro estão limitadas as taxas médias de mercado", que nada mais são do que a média aritmética de cada produto bancário, as quais são apenas calculadas e divulgadas pelo Banco Central, sem qualquer interferência deste. Situação esta, que limita o Estado a utilização de seus dois "players" no mercado, a Caixa Econômica Federal - empresa pública federal - e o Banco do Brasil - sociedade de economia mista com controle acionário do Governo Federal, para que reduzam suas taxas para influenciar, através da competitividade de mercado, que as demais instituições sejam obrigadas a seguir por um mesmo caminho.

Como forma de responder o segundo questionamento da pesquisa, verificou-se que os Tribunais brasileiros, embora existam vozes divergentes quase inaudíveis, não admitem a aplicação do Código de Defesa do Consumidor de forma direta para a limitação da taxa de juros aplicadas pelo mercado, as quais, conforme já observado, desde que contratadas regularmente, só podem sofrer restrições estatais quando ultrapassarem a taxa média de mercado.

Desta sorte, tem-se prejudicada a segunda hipótese da pesquisa, porquanto embora alguns autores indiquem os perigos de uma política de juros bancários sem qualquer limite, no ponto de vista da sustentabilidade econômica do país, os Tribunais não parecem seguir estas indicações, mantendo uma ideologia liberal de aplicação da lei nesta seara, impedindo assim uma atuação mais ativa do Estado.

Finalmente, pode-se afirmar que as perspectivas que se apresentam a economia e ao mundo do trabalho não são muitas boas, assim, é necessário buscar a participação efetiva de todos os trabalhadores no processo de renovação das bases políticas e econômicas. 
OLIVEIRA, Rafael Niebuhr Maia de; SILVA, Everaldo da. Intervenção estatal nas taxas de juros remuneratórios aplicadas pelas instituições financeiras aos consumidores no Brasil. Revista Eletrônica Direito e Política, Programa de Pós-Graduação Stricto Sensu em Ciência Jurídica da UNIVALI, Itajaí, v.12, n.3, $3^{\circ}$ quadrimestre de 2017. Disponível em: www.univali.br/direitoepolitica - ISSN 19807791

\section{REFERÊNCIAS DAS FONTES CITADAS}

ARCHERO JUNIOR, Aquiles; CONTE, Alberto. Dicionário de sociologia. 2. ed. São Paulo: Brasil, 1939.

BAKAN, Joel. A corporação, a busca patológica por lucro e poder. Tradução por Camila Werner. São Paulo: Novo Conceito Editora, 2008. 272 p.

BRASIL. Constituição da república federativa do Brasil. Brasília, DF: Senado, 1988.

Lei n. 8.313, de 23 de dezembro de 1991. Restabelecem princípios da Lei n. 7.505, de 2 de julho de 1986, institui o Programa Nacional de Apoio à Cultura (Pronac) e dá outras providências. Disponível em: <http://www.planalto.gov.br>. Acesso em: 10 mar. 2014.

Lei no 8.078, de 11 de setembro de 1990. Código de Defesa do Consumidor. Dispõe sobre a proteção do consumidor e dá outras providências. Publicado no DOU de 12.9.1990 - Edição extra e retificado em 10.1.2007. Disponível em <http://www.planalto.gov.br/ccivil_03/leis/l8078.htm>. Acesso 25. mai. 2014

Superior Tribunal de Justiça (STJ). REsp 1.061.530 RS. Relator: Ministra Nancy Andrighi. Data de Julgamento: 22/10/2008. Segunda Seção. Disponível em: <https://stj.jusbrasil.com.br/jurisprudencia/2438811/recurso-especial-resp1061530-rs-2008-0119992-4/inteiro-teor-1228758>. Acesso 16. nov. 2014.

Supremo Tribunal Federal (STF). ADI-ED 2591DF. Relator: Min. Carlos Velloso. Data de Julgamento 07/06/2006. Tribunal do Pleno. Data de Publicação 29/09/2006 Disponível <https://stf.jusbrasil.com.br/jurisprudencia/760371/acao-direta-deinconstitucionalidade-adi-2591-df>. Acesso 16. nov. 2014.

Supremo Tribunal Federal (STF). AI: 759682 GO. Relator: Min. Marco Aurélio. Data de Julgamento 06/08/2009. Data de Publicação: 03/09/2009 Disponível em: <https://stf.jusbrasil.com.br/jurisprudencia/14760907/agravode-instrumento-ai-759682-go-stf>. Acesso 16. nov. 2014.

. Supremo Tribunal Federal (STF). REsp: 1112879 PR. Relator: Ministra Nancy Andrighi. Data de Julgamento: 12/05/2010. Segunda Seção. Data de Publicação: 19/05/2010. Disponível em: <https://ww2.stj.jus.br/processo/revista/inteiroteor/?num_registro $=200300397$ 915\&dt_publicacao=01/12/2003>. Acesso 16. nov. 2014.

Tribunal Regional Federal da $5^{a}$ Região. (TRF-5). AC: 75595020124058200. Relator: Desembargadora Federal Margarida Cantarelli. Data de Julgamento: 25/02/2014. Quarta Turma. Data de Publicação: 06/03/2014. Disponível em: <https://trf- 
OLIVEIRA, Rafael Niebuhr Maia de; SILVA, Everaldo da. Intervenção estatal nas taxas de juros remuneratórios aplicadas pelas instituições financeiras aos consumidores no Brasil. Revista Eletrônica Direito e Política, Programa de Pós-Graduação Stricto Sensu em Ciência Jurídica da UNIVALI, Itajaí, v.12, n.3, $3^{\circ}$ quadrimestre de 2017. Disponível em: www.univali.br/direitoepolitica - ISSN 19807791

5.jusbrasil.com.br/jurisprudencia/25012448/ac-apelacao-civel-ac-

75595020124058200-trf5>. Acesso 16. nov. 2014. Grifei.

BUCKINGHAN, Will; BURHHAM, Douglas; HILL, Clive. et al. O livro da filosofia. São Paulo: Globo, 2011.

CAMARA DOS DEPUTADOS. Proposta de emenda constitucional n. 150 de 2003. Disponível em: <http://www.camara.gov.br>. Acesso em: 28 dez. 2014.

CERQUEIRA, H. e AMORIM, W. Evolução e característica do emprego no Setor Bancário. In: CARLEIAL, L. e VALLE, R. Reestruturação produtiva e mercado de trabalho no Brasil, São Paulo: Hucitec/ABET, 1997.

CHANG, Ha-Joon. Chutando a escada - a estratégia do desenvolvimento em perspectiva histórica. São Paulo: Editora UNESP, 2004, p. 15.

CHESNAIS, François. A Mundialização do Capital. São Paulo: Xamã, 1996.

FERNANDES, Florestan. A Revolução Burguesa no Brasil - Ensaio de Interpretação Sociológica. 3a edição, Rio de Janeiro: Zahar Editores, 1981.

FERREIRA, Aurélio Buarque de Holanda. Aurélio século XXI dicionário da língua portuguesa. Rio de Janeiro: Nova Fronteira, 1999.

FIORI, J.L. "Ajuste, Transição e Governabilidade: o Enigma Brasileiro". In: TAVARES, M.C. e FIORI, J.L. Desajuste Global e Modernização Conservadora. Rio de Janeiro: Paz e Terra, 1993.

FLEURY, Laurent. Sociologia da cultura e das práticas culturais. São Paulo: SENAC, 2009.

FREITAS, M.C. e PRATES, D. "Abertura Financeira na América Latina: as experiências da Argentina, Brasil e México. In: Revista Economia e Sociedade. Campinas, 1998.

JOHNSON, Allan G. Dicionário de sociologia - guia prático da linguagem sociológica. Rio de Janeiro: Zahar, 1997.

MINELLA, Ary. Banqueiros, Organização e Poder no Brasil. Rio de Janeiro: Espaço e Tempo/ANPOCS, 1988.

MARX, Karl. O Capital, Crítica da Economia Política. Livro I, vol.2, 12a edição, Rio de Janeiro: Bertrand Brasil, 1989a.

MARX, K. O Capital - Crítica da Economia Política. Livro I, vol. 1, 13a. Edição. Rio de Janeiro: Bertrand Brasil, 1989b.

MINAS GERAIS, Tribunal de Justiça. (TJ-MG). AC: 10145095088863001 MG. Relator: José de Carvalho Barbosa. Data de Julgamento: 13/02/2014. Câmaras Cíveis. $13^{\mathrm{a}}$ Câmara Cível. Disponível em: <https://tj- 
OLIVEIRA, Rafael Niebuhr Maia de; SILVA, Everaldo da. Intervenção estatal nas taxas de juros remuneratórios aplicadas pelas instituições financeiras aos consumidores no Brasil. Revista Eletrônica Direito e Política, Programa de Pós-Graduação Stricto Sensu em Ciência Jurídica da UNIVALI, Itajaí, v.12, n.3, 30 quadrimestre de 2017. Disponível em: www.univali.br/direitoepolitica - ISSN 19807791

mg.jusbrasil.com.br/jurisprudencia/119378837/apelacao-civel-ac10145095088863001-mg/inteiro-teor-119378880>. Acesso 16. nov. 2014.

OLIVEIRA. Eduardo Ribeiro de. A fixação da taxa de juros e o Código de Defesa do Consumidor. Revista Jus Navigandi. Teresina, ano. 14. no 2323. 10. Nov. 2009. Disponível em <http://jus.com.br/artigos/13829. Acesso em: 14 jun. 2015.

PRATES, D. Abertura Financeira e Vulnerabilidade Externa: A Economia Brasileira Na Década de 90. Dissertação de Mestrado, Instituto de Economia da Unicamp. Campinas, 1997.

RIZZARDO, Arnaldo. Juros no código civil de 2002. Revista de Direito Bancário, do Mercado de capitais e da Arbitragem. São Paulo: Editora Revista dos Tribunais. Ano 6, n. 22, outubro-dezembro de 2003.

SCAVONE JUNIOR, Luiz Antonio. Direito Imobiliário: Teoria e Prática. 7. ed. Rio de Janeiro: Forense, 2014.

SINGER, Paul. A crise do "Milagre": Interpretação Crítica da Economia Brasileira. Rio de Janeiro: Paz e Terra, 1976.

Submetido em: agosto de 2016

Aprovado em: outubro de 2017 